\title{
APOE polymorphism is associated with lipid profile, but not with arterial stiffness in the general population
}

\author{
Rafael O Alvim', Silvia RS Freitas ${ }^{1}$, Noely E Ferreira ${ }^{1}$, Paulo CJL Santos ${ }^{1}$, Roberto S Cunha ${ }^{2}$, José G Mill², \\ José E Krieger', Alexandre C Pereira ${ }^{1 *}$
}

\begin{abstract}
Background: Cardiovascular diseases (CVD) are the main cause of death and disability in developed countries. In most cases, the progress of CVD is influenced by environmental factors and multifactorial inheritance. The purpose of this study was to investigate the association between APOE genotypes, cardiovascular risk factors, and a noninvasive measure of arterial stiffness in the Brazilian population.

Methods: A total of 1493 urban Brazilian individuals were randomly selected from the general population of the Vitoria City Metropolitan area. Genetic analysis of the APOE polymorphism was conducted by PCR-RFLP and pulse wave velocity analyzed with a noninvasive automatic device.

Results: Age, gender, body mass index, triglycerides, creatinine, uric acid, blood glucose, blood pressure phenotypes were no different between $\varepsilon 2, \varepsilon 3$ and $\varepsilon 4$ alleles. The $\varepsilon 4$ allele was associated with higher totalcholesterol ( $p<0.001)$, LDL-C $(p<0.001)$, total-cholesterol/HDL-C ratio $(p<0.001)$, LDL/HDL-C ratio $(p<0.001)$, lower HDL-C values $(p<0.001)$ and higher risk to obesity $(\mathrm{OR}=1.358,95 \% \mathrm{Cl}=1.019-1.811)$ and hyperuricemia $(\mathrm{OR}=1.748,95 \% \mathrm{Cl}=1.170-2.611)$. Nevertheless, pulse wave velocity $(\mathrm{p}=0.66)$ measures were no different between genotypes. The significant association between APOE genotypes and lipid levels persisted after a 5-year follow-up interval, but no interaction between time and genotype was observed for lipids longitudinal behavior.

Conclusion: The $\varepsilon 4$ allele of the APOE gene is associated with a worse lipid profile in the Brazilian urban population. In our relatively young sample, the observed effect of APOE genotype on lipid levels was not translated into significant effects in arterial wall stiffness.
\end{abstract}

\section{Background}

Cardiovascular diseases (CVD) are the main cause of death and disability in developed countries. In most cases, the progress of CVD is influenced by multifactorial inheritance and environmental factors [1-4]. Lipoprotein disorders such as elevated low-density lipoprotein cholesterol (LDL-C $\geq 160 \mathrm{mg} / \mathrm{dL}$ ), low high-density lipoprotein cholesterol (HDL-C $<40 \mathrm{mg} / \mathrm{dL}$ ) and elevated concentration of triglycerides (TG $\geq 150 \mathrm{mg} / \mathrm{dL}$ ) are considered significant risk factors in the pathogenesis of CVD [5].

* Correspondence: alexandre.pereira@incor.usp.br

'Heart Institute (InCor), University of São Paulo Medical School, Brazil

Full list of author information is available at the end of the article
Apolipoprotein E (ApoE) is a glycoprotein that plays a fundamental role in the lipid metabolism. ApoE participates in the clearance of chylomicron remmants and very low-density lipoprotein (VLDL) by serving as a ligand for LDL receptors [6]. It is also important for intestinal cholesterol absorption [7] and plasma lipid maintenance [8]. The APOE gene, located on chromosome 19 [9], is composed by three alleles $(\varepsilon 2, \varepsilon 3$ and $\varepsilon 4)$ that give rise to six different genotypes $(\varepsilon 2 / 2, \varepsilon 2 / 3, \varepsilon 2 / 4$, $\varepsilon 3 / 3, \varepsilon 3 / 4$, and $\varepsilon 4 / 4$ ) [6]. The $\varepsilon 3$ allele differs from the $\varepsilon 2$ allele by an amino acid substitution of arginine for cysteine at codon 158 , while the $\varepsilon 4$ differs from $\varepsilon 3$ by a substitution of arginine for cysteine at residue 112 [10-12]. Many studies assessing the role of APOE polymorphism on plasma lipids have shown that the 
presence of the $\varepsilon 4$ allele is associated with elevations in LDL-C, while the presence of $\varepsilon 2$ is associated with decreased levels of LDL-C [13]. Moreover, some studies have reported that the $\varepsilon 4$ allele is associated with coronary heart disease [14] although most of these have been carried out in male subjects.

After the discovery of the $A P O E$ gene and knowledge of its genetic variants, several studies have demonstrated the association between the APOE polymorphisms and chronic conditions, such as Alzheimer's disease [15], age-related cognitive decline [16], osteoporosis [17], breast cancer [18], end-stage renal disease [19], atherosclerosis [8], diabetes [20], coronary disease [21] and longevity [22]. Based on these, we aimed to assess the relation between $A P O E$ genotype groups with the prevalence of the major CVD risk factors and its possible association with the evolution of the studied phenotypes in a longitudinal study of Brazilian subjects randomly selected from an ethnically mixed urban population.

Our hypothesis was that individuals carrying the $\varepsilon 4$ allele had a worse lipid profile when compared with $\varepsilon 2$ and $\varepsilon 3$ alleles carriers of the $A P O E$ polymorphism and that this worse profile would be translated into significantly different measures of arterial stiffness.

\section{Methods}

\section{Study Design and Participants}

A cross-sectional study of risk factors for cardiovascular diseases was performed in the urban population of the Vitória city, Brazil, using the WHO-MONICA project guidelines [23]. In the first stage of the study, conducted in 1999, 1493 Brazilians of either gender, aged 25 to 64 years were chosen according to the nearest birthday [24]. All participants were submitted to complete clinical and laboratorial investigations for CVD risk factors.

This study was approved by the Ethics Committee for Research on Human Subject of the Espírito Santo Federal University, and all subjects gave written informed consent to participate.

\section{Risk Factors Assessment}

\section{Anthropometrical Investigations}

Weight and height were measured according to a standard protocol, with participants wearing light clothing and no shoes. Height was measured in centimeters and weight in kilograms using a calibrated balance. Body mass index (BMI) was calculated and obesity defined as $\mathrm{BMI} \geq 30 \mathrm{Kg} / \mathrm{m}^{2}$ [25]. Individuals who had ever smoked more than five cigarettes per day for the last year were classified as smokers [26]. Participants were also submitted to an ethnic classification according to a validated questionnaire for the Brazilian population [27]. Subjects were classified as Caucasian or Afro-descendent according to a set of phenotypic characteristics (skin color, hair texture, shape of the nose and aspect of the lip). On the basis of these characteristics, mulattos are considered racially mixed subjects.

\section{Blood Pressure Phenotype Determination}

Blood pressure was measured in the sitting position with the use of a standard mercury sphygmomanometer on the left arm after 5 minutes' rest. The first and fifth phases of Korotkoff sounds were used for systolic (SBP) and diastolic pressure (DBP), respectively. The SBP and DBP were calculated from two readings with a minimal interval of 10 minutes. Hypertension was defined as mean SBP $\geq 140 \mathrm{mmHg}$ and/or DBP $\geq 90 \mathrm{mmHg}$ or use of anti-hypertension drugs [28]. Pulse pressure (PP) was the difference between SBP and DBP. The mean blood pressure (MBP) was calculated as the mean pulse pressure added to one-third of the DBP.

\section{Pulse wave measurements}

The Carotid-femoral pulse wave velocity (PWV) was analyzed with a noninvasive automatic device (Complior; Colson; Garges les Gonesses, France) by an experienced observer blinded to the clinical characteristics. Briefly, common carotid artery and femoral artery pressure waveforms were recorded noninvasively using a pressure- sensitive transducer (TY-306-Fukuda; Fukuda; Tokyo, Japan). The distance between the recording sites (D) was measured, and PWV was automatically calculated as $\mathrm{PWV}=\mathrm{D} / \mathrm{t}$, where $(\mathrm{t})$ means pulse transit time. Thirty measurements were repeated over 10 different cardiac cycles, and the mean is used for the final analysis. Because systolic BP has direct influence on PWV, we also adjusted PWV for the mean systolic BP in all groups. The validation of this automatic method and its reproducibility has been previously described [29].

\section{Biochemical Measurement}

Blood glucose, TG, lipoprotein fractions and uric acid were assayed by standard techniques in 12-h fasting blood samples [30].This study, diabetes was defined as fasting glucose $\geq 126 \mathrm{mg} / \mathrm{dL}$ or use of hypoglycemic drugs. Abnormal biochemical levels were identified when total-cholesterol $(\mathrm{TC}) \geq 200 \mathrm{mg} / \mathrm{dL}, \mathrm{TG} \geq 150$ $\mathrm{mg} / \mathrm{dL}, \mathrm{LDL}-\mathrm{C} \geq 160 \mathrm{mg} / \mathrm{dL}, \mathrm{HDL}-\mathrm{C}<40 \mathrm{mg} / \mathrm{dL}$ and uric acid $\geq 7.0 \mathrm{mg} / \mathrm{dL}[5,31]$.

\section{DNA Extraction and APOE genotyping}

Genomic DNA was extracted from leukocytes in samples of whole blood, following a standard salting-out technique [32]. Genotypes were detected by polymerase chain reaction followed by restriction fragment length polymorphism analysis as previously described [33]. In addition, we have genotyped samples for the APOE polymorphisms (rs7412 and rs429358) by an additional method (HRM analysis - high resolution melting). Briefly, PCR with a fluorescent DNA-intercalating SYTO9 $^{\circ}$ (Invitrogen, Carlsbad, USA) was performed 
using the primer sequences 5'-GCCGATGACCTGCAGAAG-3' and 5'-CACGCGGCCCTGTTCCAC-3' (fragment size 117 pairs base) and 5'-GCGGACATGGAGGACGTG-3' and 5'- AGCTCCTCGGTGCTCTGG-3' (fragment size 83 pairs base), for rs7412 and rs429358, respectively. In the HRM phase, Rotor Gene $6000^{\circ}$ (Qiagen, Courtaboeuf, France) measured the fluorescence in each $0.1^{\circ} \mathrm{C}$ temperature increase in the range of $70-94^{\circ} \mathrm{C}$. Melting curves were generated by the decrease in fluorescence with the increase in the temperature; nucleotide changes resulting from different curve patterns were analyzed and genotyped (Figure 1). Samples of the three observed curves were sequenced (ABI 3500XL Sequencer ${ }^{\odot}$, Applied Biosystems, Foster City, CA, USA) to confirm the genotypes indicated by HRM.

Quality control for the APOE polymorphisms (rs7412 and rs429358) was assessed by randomly selecting 96 samples to be re-genotyped using a high resolution melting method (HRM analysis, Rotor Gene 6000', Qiagen, Courtaboeuf, France) by two independent technicians and these results were $100 \%$ concordant.

\section{Statistical Analysis}

To evaluate the effect of $A P O E$ genotypes on cardiovascular risk factors, subjects were categorized into three groups: $\varepsilon 2$ carriers $(\varepsilon 2 / \varepsilon 2+\varepsilon 2 / \varepsilon 3$ genotypes), $\varepsilon 3$ carriers $(\varepsilon 3 / \varepsilon 3$ genotype) and $\varepsilon 4$ carriers $(\varepsilon 4 / \varepsilon 4+\varepsilon 3 / \varepsilon 4$ genotypes) [34]. In each model, the homozygous $\varepsilon 3 / \varepsilon 3$ genotypes formed the reference group. Thirty-two individuals $(2.3 \%)$ with $\varepsilon 2 / \varepsilon 4$ genotype were excluded from the analysis because of the putative opposite effects of these two alleles on LDL-C levels [35].

Differences in the baseline cardiovascular risk characteristics across the $A P O E$ groups were tested by One-
Way ANOVA for continuous variables, and $\chi^{2}$ test for categorical parameters. Table 1 shows the comparison of data among all allelic groups. All variables were adjusted for ethnicity, age and gender, except the PWV was adjusted for age, SBP and ethnicity.

Logistic regression analysis was carried out to estimate the odds ratio (OR), with 95\% confidence intervals (CI), in order to assess genetic risk factors for common cardiovascular risk. The risk analysis was performed comparing all three groups together. In the Table 2, we present risk estimative for E2 and E4 allele carriers against all other allele groups.

Quantitative variables were expressed as the mean \pm standard deviation, while qualitative variables were expressed as percentage. Hardy-Weinberg equilibrium for the distribution of the genotype groups was estimated using the Haploview software. All statistical analyses were carried out using SPSS software (v. 16.0), with the level of significance set at $\mathrm{p}<0.05$.

\section{Results}

The frequency of $A P O E$ genotypes among 1461 participants were: $\varepsilon 2 / \varepsilon 2-0.4 \%, \varepsilon 2 / \varepsilon 3-9.7 \%, \varepsilon 2 / \varepsilon 4-2.3 \%, \varepsilon 3 /$ $\varepsilon 3-61.0 \%, \varepsilon 3 / \varepsilon 4-24.4 \%$ and $\varepsilon 4 / \varepsilon 4-2.2 \%$. The allele frequencies were: $\varepsilon 2-10.1 \%$, $\varepsilon 3-61.0 \%$ and $\varepsilon 4-26.6 \%$. The genotype distributions for $A P O E$ polymorphisms (rs7412 and rs429358) were in Hardy-Weinberg equilibrium ( $\mathrm{p}>0.05$ ). The ethnicity proportion was different among the $A P O E$ allele groups ( $\mathrm{p}=0.002)$, where the number of Caucasians is higher than Afro-descendent in the $\varepsilon 3$ allele group (67.0\% vs. $51.6 \%$, respectively). Comparative analysis failed to indicate a significant difference among $A P O E$ groups and age $(\mathrm{p}=0.28)$, gender $(\mathrm{p}=$ $0.13)$, diabetes $(\mathrm{p}=0.81)$ and smoking status $(\mathrm{p}=0.66)$ (Table 1).
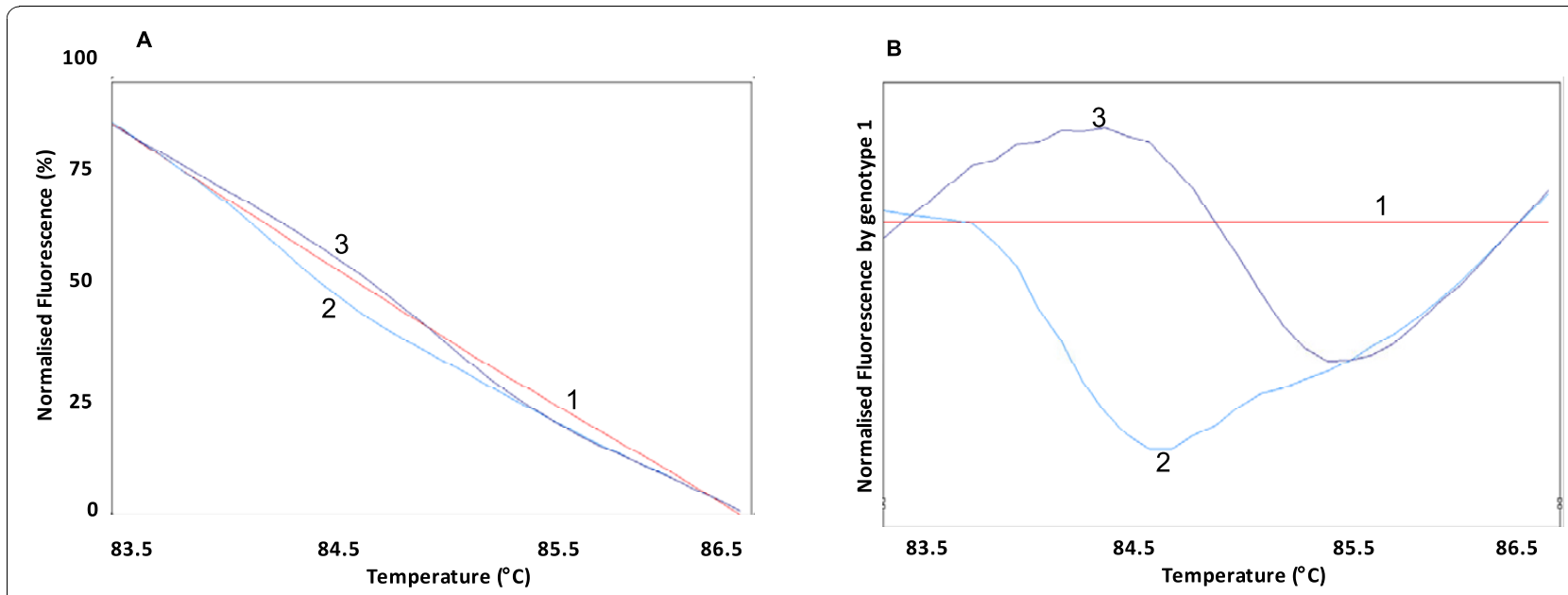

Figure 1 Genotyping of rs7412 through HRM analysis. A: Normalized fluorescence by temperature. B: Normalized fluorescence (based on genotype 1) by temperature. 1: wild-type genotype; 2: heterozygous genotype; 3: homozygous genotype for the APOE rs7412 polymorphism. 
Table 1 Baseline characteristics of participants encoding $\varepsilon 2, \varepsilon 3$ and $\varepsilon 4$ alleles of the APOE polymorphism

\begin{tabular}{|c|c|c|c|c|}
\hline Subject Characteristics n, (\%) & $\varepsilon 2180(12.3 \%)$ & ع3 893 (61.1\%) & $\varepsilon 4388(26.6 \%)$ & $p$ value \\
\hline Gender, male & $76(42.2 \%)$ & $433(48.5 \%)$ & $169(43.6 \%)$ & 0.13 \\
\hline \multicolumn{5}{|l|}{ Ethnicity } \\
\hline African descendent & $19(15.6 \%)$ & $63(51.6 \%)$ & $40(32.8 \%)$ & \\
\hline Caucasian descendent & $50(9.1 \%)$ & $367(67.0 \%)$ & $131(23.9 \%)$ & 0.002 \\
\hline Mulatto & $111(14.1 \%)$ & $463(58.5 \%)$ & $217(27.4 \%)$ & \\
\hline Smoking status, smokers (\%) & $43(23.9 \%)$ & $211(23.6 \%)$ & $101(26.0 \%)$ & 0.66 \\
\hline Diabetes (\%) & $13(7.2 \%)$ & $70(7.8 \%)$ & $34(8.7 \%)$ & 0.81 \\
\hline Age, years & $43.8 \pm 10.6$ & $45.1 \pm 10.9$ & $44.5 \pm 10.8$ & 0.28 \\
\hline $\mathrm{BMI}, \mathrm{kg} / \mathrm{m} 2$ & $25.8 \pm 4.7$ & $26.3 \pm 4.9$ & $26.4 \pm 4.9$ & 0.27 \\
\hline SBP, $\mathrm{mmHg}$ & $125.9 \pm 19.7$ & $128.1 \pm 21.5$ & $129.4 \pm 22.6$ & 0.15 \\
\hline $\mathrm{DBP}, \mathrm{mmHg}$ & $83.3 \pm 13.9$ & $84.5 \pm 14.1$ & $85.1 \pm 14.1$ & 0.34 \\
\hline $\mathrm{PP}, \mathrm{mmHg}$ & $42.6 \pm 11.4$ & $43.7 \pm 13.7$ & $44.3 \pm 14.3$ & 0.34 \\
\hline $\mathrm{MBP}, \mathrm{mmHg}$ & $97.5 \pm 15.2$ & $99.0 \pm 15.8$ & $99.8 \pm 16.1$ & 0.21 \\
\hline $\mathrm{PWV}, \mathrm{m} / \mathrm{s}$ & $10.0 \pm 2.1$ & $9.8 \pm 2.2$ & $9.8 \pm 2.1$ & 0.66 \\
\hline Triglycerides, mg/dL & $133.7 \pm 99.1$ & $133.9 \pm 124.4$ & $145.9 \pm 148.6$ & 0.28 \\
\hline Total cholesterol, mg/dL & $201.4 \pm 50.6$ & $215.2 \pm 48.3^{*}$ & $218.6 \pm 44.6 \dagger$ & $<0.001$ \\
\hline $\mathrm{HDL}-\mathrm{C}, \mathrm{mg} / \mathrm{dL}$ & $48.8 \pm 14.6$ & $45.5 \pm 12.7^{*}$ & $43.2 \pm 10.1 \dagger \neq$ & $<0.001$ \\
\hline $\mathrm{LDL}-\mathrm{C}, \mathrm{mg} / \mathrm{dL}$ & $125.3 \pm 35.8$ & $143.6 \pm 38.9^{*}$ & $147.9 \pm 39.6 \dagger$ & $<0.001$ \\
\hline VLDL - C, mg/dL & $25.3 \pm 17.2$ & $25.5 \pm 22.9$ & $26.2 \pm 15.5$ & 0.81 \\
\hline Total cholesterol/HDL - C ratio & $4.3 \pm 1.4$ & $5.0 \pm 1.5^{*}$ & $5.3 \pm 1.5 \dagger$ & $<0.001$ \\
\hline LDL - C/HDL - C ratio & $2.8 \pm 1.0$ & $3.4 \pm 1.2^{*}$ & $3.6 \pm 1.3 \dagger \neq$ & $<0.001$ \\
\hline Glucose, mg/dL & $103.9 \pm 30.1$ & $105.8 \pm 33.0$ & $104.4 \pm 31.0$ & 0.64 \\
\hline Creatinine, mg/dL & $0.99 \pm 0.19$ & $0.97 \pm 0.20$ & $0.96 \pm 0.20$ & 0.16 \\
\hline Uric acid, mg/dL & $4.7 \pm 1.4$ & $4.8 \pm 1.5$ & $5.0 \pm 1.6 \dagger$ & 0.04 \\
\hline
\end{tabular}

BMI, body mass index; SBP, systolic blood pressure; DBP, diastolic blood pressure; PP, pressure pulse; MBP, mean blood pressure; PWV, pulse wave velocity; HDL $C$, high-density lipoprotein cholesterol; LDL - C, low-density lipoprotein cholesterol; VLDL - C, very-low-density lipoprotein cholesterol.

$\varepsilon 2$ allele $=\varepsilon 2 / \varepsilon 2+\varepsilon 2 / \varepsilon 3$ genotypes; $\varepsilon 3$ allele $=\varepsilon 3 / \varepsilon 3$ genotype; $\varepsilon 4$ allele $=\varepsilon 3 / \varepsilon 4+\varepsilon 4 / \varepsilon 4$ genotypes.

${ }^{*} \varepsilon 2$ vs $\varepsilon 3, \mathrm{p}<0.05 ; \dagger \varepsilon 2$ vs $\varepsilon 4, \mathrm{p}<0.05 ; \neq \varepsilon 3$ vs $\varepsilon 4, \mathrm{p}<0.05$.

All values were adjusted for ethnicity, age and gender except the PWV was adjusted for age, SBP and ethnicity.

\section{Association Between Hemodynamic Phenotypes and APOE Polymorphism}

Hemodynamic phenotypes of SBP $(\mathrm{p}=0.15)$, DBP $(\mathrm{p}=$ $0.34)$, MBP $(\mathrm{p}=0.21)$, PP $(\mathrm{p}=0.34)$ and PWV $(\mathrm{p}=$ $0.66)$ showed no association with $A P O E$ allele groups (Table 1). Similarly, risk analysis performed by multiple logistic regression failed to detect significant genetic risk for high SBP $(\varepsilon 2$ carriers: OR $=0.786,95 \% \mathrm{CI}=0.526$ 1.173, $\varepsilon 4$ carriers: $\mathrm{OR}=1.140,95 \% \mathrm{CI}=0.858-1.515$ ) and high DBP $(\varepsilon 2$ carriers: $\mathrm{OR}=1.096,95 \% \mathrm{CI}=0.776-$ $1.549)$ and $\varepsilon 4$ carriers: $\mathrm{OR}=0.968,95 \% \mathrm{CI}=0.745$ 1.257) (Table 2).

Table 2 Analysis of the cardiovascular risk factors associated with APOE polymorphism

\begin{tabular}{|c|c|c|c|c|c|c|}
\hline \multirow[b]{3}{*}{ VARIABLES } & \multicolumn{6}{|c|}{ APOE ALLELES } \\
\hline & \multicolumn{3}{|c|}{$\varepsilon 2$} & \multicolumn{3}{|c|}{84} \\
\hline & OR & $\mathrm{Cl} 95 \%$ & $p$ value & OR & Cl 95\% & $p$ value \\
\hline Total cholesterol & 0.44 & $0.319-0.618$ & $<0.001$ & 1.571 & $1.218-2.026$ & 0.001 \\
\hline $\mathrm{HDL}-\mathrm{C}$ & 0.584 & $0.400-0.854$ & 0.005 & 1.271 & $0.982-1.644$ & 0.07 \\
\hline LDL - C & 0.401 & $0.262-0.614$ & $<0.001$ & 1.738 & $1.343-2.250$ & $<0.001$ \\
\hline Uric Acid & 0.500 & $0.237-1.056$ & 0.07 & 1.748 & $1.170-2.611$ & 0.006 \\
\hline SBP & 0.786 & $0.526-1.173$ & 0.13 & 1.140 & $0.858-1.515$ & 0.37 \\
\hline DBP & 1.096 & $0.776-1.549$ & 0.60 & 0.968 & $0.745-1.257$ & 0.81 \\
\hline BMI & 0.717 & $0.466-1.104$ & 0.13 & 1.358 & $1.019-1.811$ & 0.04 \\
\hline
\end{tabular}

Adjusted values for ethnicity, gender and age. 


\section{Association Between Biochemical and Metabolic Phenotypes and APOE Polymorphism}

Biochemical measurement of TC, LDL-C, HDL-C, TC/ HDL ratio and LDL-C/HDL and uric acid were associated with the $A P O E$ polymorphism, even after adjustment for ethnicity, age and gender. Values of $\mathrm{TC}(\mathrm{p}<$ $0.001)$, LDL-C ( $p<0.001)$, TC/HDL ratio $(\mathrm{p}<0.001)$ and LDL/HDL-C ratio were higher in $\varepsilon 4$ and $\varepsilon 3$ when compared to $\varepsilon 2$ allele carriers. However, for TC, LDL-C and TC/HDL-C no difference was observed between $\varepsilon 2$ and $\varepsilon 3$ alleles $(\mathrm{p}>0.05)$. The HDL- $C$ values $(\mathrm{p}<0.001)$ were lower in $\varepsilon 4$ and $\varepsilon 3$ alleles when compared with $\varepsilon 2$ allele carriers. In addition, $\varepsilon 3$ carriers showed higher HDL-C values when compared with $\varepsilon 4$ allele carriers. The uric acid values $(\mathrm{p}=0.04)$ were lower in $\varepsilon 2$ allele when compared with $\varepsilon 4$ allele carriers. Other variables, such as TG $(\mathrm{p}=0.28)$, VLDL-C $(\mathrm{p}=0.81)$, glucose $(\mathrm{p}=$ $0.64)$, creatinine $(\mathrm{p}=0.16)$ and BMI $(\mathrm{p}=0.27)$ failed to show association with $A P O E$ groups (Table 1 ).

The $\varepsilon 2$ allele confers protection for high $\mathrm{TC}(\mathrm{OR}=$ $0.444,95 \% \mathrm{CI}=0.319-0.618)$, low HDL-C $(\mathrm{OR}=0.584$, $95 \% \mathrm{CI}=0.400-0.854)$, high LDL-C $(\mathrm{OR}=0.401,95 \%$ $\mathrm{CI}=0.262-0.614)$, while $\varepsilon 4$ allele confers risk for elevated levels of TC $(\mathrm{OR}=1.571,95 \% \mathrm{CI}=1.218-2.026)$, LDL-C $(\mathrm{OR}=1.738,95 \% \mathrm{CI}=1.343-2.250)$, uric acid $(\mathrm{OR}=1.748,95 \% \mathrm{CI}=1.170-2.611)$ and $\mathrm{BMI}(\mathrm{OR}=$ $1.358,95 \%$ CI $=1.019-1.811$ ) (Table 2).

\section{Discussion}

The main finding of the present study was that $A P O E$ genetic variability is associated with cardiovascular risk factors in a Brazilian urban population. Increased LDL$\mathrm{C}, \mathrm{TC}, \mathrm{TC} / \mathrm{HDL}-\mathrm{C}$ ratio, $\mathrm{LDL}-\mathrm{C} / \mathrm{HDL}-\mathrm{C}$ ratio and decreased HDL-C values were observed in individuals harboring the $\varepsilon 4$ allele. However, this genetic variant was not associated with the arterial stiffness phenotype.

Corroborating our results, Medina-Urrutia et al [13] demonstrated associations between the $\varepsilon 4$ allele of the $A P O E$ polymorphism and higher concentrations of TC, LDL-C and lower HDL-C levels when compared with the $\varepsilon 2$ allele carriers in Mexican adolescents. Similarly, Shu Liang et al [36] studying 168 healthy Chinese individuals showed associations between the $\varepsilon 4$ allele with increased TC and LDL-C values. However, HDL-C was not associated with the genetic variant studied. In the Brazilian population, de-Andrade et al [37] studying individuals of both genders described associations between the $\varepsilon 4$ allele and higher TG and total and nonHDL levels only in women. Additionally, Mendes-Lana et al [38] showed that $\varepsilon 4$ allele carriers present increased risk for dyslipidemia when compared to $\varepsilon 2$ allele carriers. However, De França et al [39] failed to demonstrate an association between the $\varepsilon 4$ allele with increased TC and LDL-C values in healthy children, suggesting that at least part of the described effect is age-dependent. In fact, although a large number of studies show associations between $A P O E$ polymorphisms with cardiovascular risk and lipid profile phenotypes in different populations $[40,41]$, some studies failed to demonstrate this association $[42,43]$.

Some functional studies may help in explaining our findings. Miettinen et al [44] found a significant higher cholesterol absorption in subjects with $\varepsilon 3$ and $\varepsilon 4$ alleles compared with those carrying the $\varepsilon 2$ allele after a normal diet. In addition, Weintraub et al [45] showed that the slower hepatic clearance of dietary fat in $\varepsilon 2 / 3$ subjects could result in up-regulation of LDL receptors and a subsequent decrease in plasma LDL-C levels.

Arterial stiffness and hypertension are the most important risk factors for cardiovascular diseases $[2,46]$. Several studies have demonstrated association of these with the metabolic profile $[47,48]$. The present study failed to demonstrate an association between $A P O E$ polymorphisms with blood pressure phenotypes and arterial stiffness. Corroborating some results of this study, Fuzikawa et al [49]studied 1406 Brazilian elderly individuals and found no association between $A P O E$ genotype and hypertension. Similarly, Carmo-Martins et al [50] studied 672 Portuguese subjects and failed to demonstrated an association with blood pressure.

Focusing on the arterial stiffness, studies [51] have showed that the unfavorable lipid profile is associated with lower arterial complacence due to reduced NO bioavailability induced by dyslipidemia. Thus, we expected $\varepsilon 4$ allele carriers of the $A P O E$ polymorphism would have a higher arterial stiffness when compared to $\varepsilon 2$ allele carriers. However, this was not evident in this study, perhaps due to the little difference in mean lipid fractions between the groups as well as the relative young age of studied individuals. Studies involving the $A P O E$ polymorphism with arterial stiffness phenotype remain scarce in the literature. Thereby, further studies involving the $A P O E$ polymorphism with arterial stiffness phenotype are needed to clarify these issues.

Classically, obesity and hyperuricemia have shown to have important roles in the development of cardiometabolic disease $[3,52,53]$. This study showed that $\varepsilon 4$ allele is associated with higher uric acid levels when compared to $\varepsilon 2$ allele carriers. In addition, the presence of the $\varepsilon 4$ allele offered increased risk for obesity and hyperuricemia. Unlike our findings, Liberopoulos et al [54] studying healthy individuals showed that the $\varepsilon 4$ allele was associated with lower uric acid levels when compared to allele $\varepsilon 2$. Similar to our study, $\varepsilon 2$ allele was associated with lower serum levels of TC. Among the mechanisms that may explain the higher prevalence of hyperuricemia in individuals carrying the $\varepsilon 4$ allele of $A P O E$ polymorphism in our study could be the hyperinsulinemia 
associated with an unfavorable lipid profile. Several studies [55] have confirmed that under-excretion of uric acid into the urine caused by the effect of insulin on the urinary tubular tract has been demonstrated with physiological hyperinsulinemia acutely reducing urinary uric acid which could lead to a higher concentration of this protein in the bloodstream. Due to the controversial results and few existing data, studies of the association between $A P O E$ polymorphism and uric acid need to be further conducted. Similarly, studies associating obesity phenotypes with $A P O E$ polymorphism have shown controversial results. Corroborating our results, CarmoMartins et al. [50] showed that obese subjects (BMI $\geq$ $30 \mathrm{Kg} / \mathrm{m}^{2}$ ) are more prevalent in the $\varepsilon 4$ allele group than in the $\varepsilon 2$ allele group. In another study, Kolovou et al [56] showed in coronary heart disease patients that the prevalence of obese individuals was higher in the $\varepsilon 4$ allele than in the $\varepsilon 2$ allele group. Nevertheless, other studies failed to show this association [57]. The relationship between dyslipidemia and obesity is well established in the literature. However, the mechanism by which apolipoprotein E would influence obesity is not clear. Karagiannides et al [58] showed through an experimental study that rat ApoE3 ${ }^{\text {knock in }}$ after a high-fat diet gained more weight than animals that did not express the APOE protein and animals that expressed isoform APOE2. Considering that in vitro receptor binding studies established that lipid-bound ApoE3 and ApoE4 have a similar affinity for LDLr, whereas lipid-bound ApoE2 has a much lower affinity [59], we hypothesize that this higher affinity of APOE4 isoform could result in increased lipid deposition in the adipose tissue.

Our study has potential limitations. First, it should be noted that the relative young age of the studied population may preclude the identification of the association between the studied genotype and measures of arterial stiffness. Second, we did not evaluate the use of cholesterol-lowering drugs, which could confound the observed associations. Finally, if we have measured insulin and urinary uric acid levels in this population, we could shed light into the proposed mechanism for the association of $A P O E$ polymorphism and serum uric acid.

In conclusion, the present study confirms the close association between $A P O E$ polymorphism and the lipid profile in individuals from the general population, but failed to show this genetic risk factor as an important modulator of arterial distensibility in this same sample.

\section{Author details \\ ${ }^{1}$ Heart Institute (InCor), University of São Paulo Medical School, Brazil. ${ }^{2}$ Department of Physiology, Espírito Santo Federal University, Brazil.}

\section{Authors' contributions}

ROA and SRSF participated in the design of the study, performed the statistical analysis and drafted the manuscript. PCILS and NEF contributed to acquisition of data and its interpretation. RSC, JGM and JEK contributed to conception and design of the study. ACP conceived of the study, participated in its design, coordination and helped to draft the manuscript. All authors read and approved the manuscript.

\section{Competing interests}

The authors declare that they have no competing interests.

Received: 6 July 2010 Accepted: 8 November 2010 Published: 8 November 2010

\section{References}

1. Kreisberg RA, Oberman A: Clinical review 141: lipids and atherosclerosis: lessons learned from randomized controlled trials of lipid lowering and other relevant studies. J Clin Endocrinol Metab 2002, 87(2):423-437.

2. Chobanian AV, Bakris GL, Black HR, Cushman WC, Green LA, Izzo JL Jr, Jones DW, Materson BJ, Oparil S, Wright JT Jr, et al: Seventh report of the Joint National Committee on Prevention, Detection, Evaluation, and Treatment of High Blood Pressure. Hypertension 2003, 42(6):1206-1252.

3. Grundy SM: Obesity, metabolic syndrome, and coronary atherosclerosis. Circulation 2002, 105(23):2696-2698.

4. Niskanen LK, Laaksonen DE, Nyyssonen K, Alfthan G, Lakka HM, Lakka TA, Salonen JT: Uric acid level as a risk factor for cardiovascular and all-cause mortality in middle-aged men: a prospective cohort study. Arch Intern Med 2004, 164(14):1546-1551.

5. Executive Summary of The Third Report of The National Cholesterol Education Program (NCEP) Expert Panel on Detection, Evaluation, And Treatment of High Blood Cholesterol In Adults (Adult Treatment Panel III). JAMA 2001, 285(19):2486-2497.

6. Mahley RW, Innerarity TL, Rall SC Jr, Weisgraber KH: Plasma lipoproteins: apolipoprotein structure and function. J Lipid Res 1984, 25(12):1277-1294.

7. Kesaniemi YA, Ehnholm C, Miettinen TA: Intestinal cholesterol absorption efficiency in man is related to apoprotein E phenotype. J Clin Invest 1987, 80(2):578-581.

8. Davignon J, Gregg RE, Sing CF: Apolipoprotein E polymorphism and atherosclerosis. Arteriosclerosis 1988, 8(1):1-21.

9. Das HK, McPherson J, Bruns GA, Karathanasis SK, Breslow JL: Isolation, characterization, and mapping to chromosome 19 of the human apolipoprotein E gene. J Biol Chem 1985, 260(10):6240-6247.

10. Kolovou G, Damaskos D, Anagnostopoulou K, Cokkinos DV: Apolipoprotein E gene polymorphism and gender. Ann Clin Lab Sci 2009, 39(2):120-133.

11. Scott J, Knott TJ, Shaw DJ, Brook JD: Localization of genes encoding apolipoproteins $\mathrm{Cl}, \mathrm{Cll}$, and $\mathrm{E}$ to the $\mathrm{p} 13$ - - cen region of human chromosome 19. Hum Genet 1985, 71(2):144-146.

12. Weisgraber $\mathrm{KH}$, Rall SC Jr, Mahley RW: Human E apoprotein heterogeneity. Cysteine-arginine interchanges in the amino acid sequence of the apo-E isoforms. J Biol Chem 1981, 256(17):9077-9083.

13. Medina-Urrutia AX, Cardoso-Saldana GC, Zamora-Gonzalez J, Liria YK, Posadas-Romero C: Apolipoprotein E polymorphism is related to plasma lipids and apolipoproteins in Mexican adolescents. Hum Biol 2004, 76(4):605-614.

14. Wilson PW, Schaefer EJ, Larson MG, Ordovas JM: Apolipoprotein E alleles and risk of coronary disease. A meta-analysis. Arterioscler Thromb Vasc Biol 1996, 16(10):1250-1255

15. Laws SM, Hone E, Gandy S, Martins RN: Expanding the association between the APOE gene and the risk of Alzheimer's disease: possible roles for APOE promoter polymorphisms and alterations in APOE transcription. J Neurochem 2003, 84(6):1215-1236.

16. Bretsky P, Guralnik JM, Launer L, Albert M, Seeman TE: The role of APOEepsilon4 in longitudinal cognitive decline: MacArthur Studies of Successful Aging. Neurology 2003, 60(7):1077-1081.

17. Shiraki M, Shiraki Y, Aoki C, Hosoi T, Inoue S, Kaneki M, Ouchi Y: Association of bone mineral density with apolipoprotein E phenotype. J Bone Miner Res 1997, 12(9):1438-1445.

18. Chang SJ, Hou MF, Tsai SM, Kao JT, Wu SH, Hou LA, Tsai LY: Association between the apolipoprotein $\mathrm{E}$ genotypes and breast cancer patients in Taiwanese. Breast Cancer Res Treat 2006, 98(1):109-113.

19. Hubacek JA, Bloudickova S, Kubinova R, Pikhart H, Viklicky O, Bobak M: Apolipoprotein E polymorphism in hemodialyzed patients and healthy controls. Biochem Genet 2009, 47(9-10):688-693. 
20. Errera Fl, Silva ME, Yeh E, Maranduba CM, Folco B, Takahashi W, Pereira AC, Krieger JE, Passos-Bueno MR: Effect of polymorphisms of the MTHFR and APOE genes on susceptibility to diabetes and severity of diabetic retinopathy in Brazilian patients. Braz J Med Biol Res 2006, 39(7):883-888.

21. Reilly $M$, Rader DJ: Apolipoprotein E and coronary disease: a puzzling paradox. PLoS Med 2006, 3(6):e258.

22. Bailleul S, Couderc R, Landais V, Lefevre G, Raichvarg D, Etienne J: Direct phenotyping of human apolipoprotein $E$ in plasma: application to population frequency distribution in Paris (France). Hum Hered 1993, 43(3):159-165.

23. The World Health Organization MONICA Project (monitoring trends and determinants in cardiovascular disease): a major international collaboration. WHO MONICA Project Principal Investigators. J Clin Epidemiol 1988, 41(2):105-114.

24. Mill JGMM, Silva IO, Marquezine AL, Ferreira AVL, Cunha RS, et al: Epidemiologia da hipertensão arterial na cidade de Vitória, Espírito Santo. Hipertensão 2004, 7(3):109-116.

25. World Health Organization. Obesity and overweight. [http://www.who. int/mediacentre/factsheets/fs311/en/index.html].

26. Freitas SR, Pereira AC, Floriano MS, Mill JG, Krieger JE: Association of alpha1a-adrenergic receptor polymorphism and blood pressure phenotypes in the Brazilian population. BMC Cardiovasc Disord 2008, 8:40.

27. Lessa I, Fonseca J: [Race, compliance to treatment and/or consultation and control of arterial hypertension]. Arq Bras Cardiol 1997, 68(6):443-449.

28. 1999 World Health Organization-International Society of Hypertension Guidelines for the Management of Hypertension. Guidelines Subcommittee. J Hypertens 1999, 17(2):151-183.

29. Asmar R, Benetos A, Topouchian J, Laurent P, Pannier B, Brisac AM, Target $R$, Levy Bl: Assessment of arterial distensibility by automatic pulse wave velocity measurement. Validation and clinical application studies. Hypertension 1995, 26(3):485-490.

30. Pereira AC, Sposito AC, Mota GF, Cunha RS, Herkenhoff FL, Mill JG, Krieger JE: Endothelial nitric oxide synthase gene variant modulates the relationship between serum cholesterol levels and blood pressure in the general population: new evidence for a direct effect of lipids in arterial blood pressure. Atherosclerosis 2006, 184(1):193-200.

31. Santos RD: [III Brazilian Guidelines on Dyslipidemias and Guideline of Atherosclerosis Prevention from Atherosclerosis Department of Sociedade Brasileira de Cardiologia]. Ara Bras Cardiol 2001, 77(Suppl 3):1-48.

32. Miller SA, Dykes DD, Polesky HF: A simple salting out procedure for extracting DNA from human nucleated cells. Nucleic Acids Res 1988 16(3):1215.

33. Wang HK, Fung HC, Hsu WC, Wu YR, Lin JC, Ro LS, Chang KH, Hwu FJ, Hsu Y, Huang SY, et al: Apolipoprotein E, angiotensin-converting enzyme and kallikrein gene polymorphisms and the risk of Alzheimer's disease and vascular dementia. J Neural Transm 2006, 113(10):1499-1509.

34. He LN, Recker RR, Deng HW, Dvornyk V: A polymorphism of apolipoprotein E (APOE) gene is associated with age at natural menopause in Caucasian females. Maturitas 2009, 62(1):37-41.

35. Ward H, Mitrou PN, Bowman R, Luben R, Wareham NJ, Khaw KT, Bingham S: APOE genotype, lipids, and coronary heart disease risk: a prospective population study. Arch Intern Med 2009, 169(15):1424-1429.

36. Liang $\mathrm{S}$, Pan M, Geng HH, Chen H, Gu LQ, Qin XT, Qian JJ, Zhu JH, Liu CF: Apolipoprotein E polymorphism in normal Han Chinese population: frequency and effect on lipid parameters. Mol Biol Rep 2009, 36(6):1251-1256.

37. de-Andrade FM, Larrandaburu M, Callegari-Jacques SM, Gastaldo G, Hutz MH: Association of apolipoprotein E polymorphism with plasma lipids and Alzheimer's disease in a Southern Brazilian population. Braz $J$ Med Biol Res 2000, 33(5):529-537.

38. Mendes-Lana A, Pena GG, Freitas SN, Lima AA, Nicolato RL, NascimentoNeto RM, Machado-Coelho GL, Freitas RN: Apolipoprotein E polymorphism in Brazilian dyslipidemic individuals: Ouro Preto study. Braz J Med Biol Res 2007, 40(1):49-56.

39. De Franca E, Alves JG, Hutz MH: Apolipoprotein E polymorphism and its association with serum lipid levels in Brazilian children. Hum Biol 2004, 76(2):267-275

40. Saidi S, Slamia LB, Ammou SB, Mahjoub T, Almawi WY: Association of apolipoprotein $\mathrm{E}$ gene polymorphism with ischemic stroke involving large-vessel disease and its relation to serum lipid levels. J Stroke Cerebrovasc Dis 2007, 16(4):160-166.

41. Kumar P, Luthra K, Dwivedi M, Behl VK, Pandey RM, Misra A Apolipoprotein $\mathrm{E}$ gene polymorphisms in patients with premature myocardial infarction: a case-controlled study in Asian Indians in North India. Ann Clin Biochem 2003, 40(Pt 4):382-387.

42. Pitsavos C, Choumerianou DM, Skoumas J, Maumus S, Stefanadis C, Dedoussis GV, Visvikis-Siest S: Apolipoprotein E polymorphism is not associated with lipid levels and coronary artery disease in Greek patients with familial hypercholesterolaemia. Clin Exp Med 2005, 5(4):196-201.

43. Gottlieb MG, Schwanke CH, Santos AF, Jobim PF, Mussel DP, da Cruz IB: Association among oxidized LDL levels, MnSOD, apolipoprotein E polymorphisms, and cardiovascular risk factors in a south Brazilian region population. Genet Mol Res 2005, 4(4):691-703.

44. Miettinen TA, Gylling $H$, Vanhanen $H$, Ollus A: Cholesterol absorption, elimination, and synthesis related to LDL kinetics during varying fat intake in men with different apoprotein E phenotypes. Arterioscler Thromb 1992, 12(9):1044-1052.

45. Weintraub MS, Eisenberg S, Breslow JL: Dietary fat clearance in normal subjects is regulated by genetic variation in apolipoprotein E. J Clin Invest 1987, 80(6):1571-1577.

46. Meaume S, Benetos A, Henry OF, Rudnichi A, Safar ME: Aortic pulse wave velocity predicts cardiovascular mortality in subjects $>70$ years of age. Arterioscler Thromb Vasc Biol 2001, 21(12):2046-2050.

47. Zanchetti A: Hyperlipidemia in the hypertensive patient. Am J Med 1994, 96(6A):3S-8S.

48. Pannier BM, Cambillau MS, Vellaud V, Atger V, Moatti N, Safar ME: Abnormalities of lipid metabolism and arterial rigidity in young subjects with borderline hypertension. Clin Invest Med 1994, 17(1):42-51.

49. Fuzikawa AK, Peixoto SV, Taufer M, Moriguchi EH, Lima-Costa MF: Association of ApoE polymorphisms with prevalent hypertension in 1406 older adults: the Bambui Health Aging Study (BHAS). Braz J Med Biol Res 2008, 41(2):89-94

50. Carmo Martins M, Lima Faleiro L, Rodrigues MO, Albergaria I, Fonseca A: [Influence of the APOE genotypes in some atherosclerotic risk factors]. Acta Med Port 2008, 21(5):433-440.

51. Vogel RA, Corretti MC, Gellman J: Cholesterol, cholesterol lowering, and endothelial function. Prog Cardiovasc Dis 1998, 41(2):117-136.

52. Hollister LE, Overall JE, Snow HL: Relationship of obesity to serum triglyceride, cholesterol, and uric acid, and to plasma-glucose levels. Am J Clin Nutr 1967, 20(7):777-782.

53. Li NF, Wang HM, Yang J, Zhou L, Yao XG, Hong J: Serum uric acid is associated with metabolic risk factors for cardiovascular disease in the Uygur population. Appl Physiol Nutr Metab 2009, 34(6):1032-1039.

54. Liberopoulos EN, Miltiadous GA, Athyros VG, Ganotakis M, Cariolou M, Bairaktari $E$, Elisaf MS: Effect of apolipoprotein $E$ polymorphism on serum uric acid levels in healthy subjects. J Investig Med 2005, 53(3):116-122.

55. Quinones Galvan A, Natali A, Baldi S, Frascerra S, Sanna G, Ciociaro D, Ferrannini E: Effect of insulin on uric acid excretion in humans. Am J Physiol 1995, 268(1 Pt 1):E1-5.

56. Kolovou GD, Anagnostopoulou KK, Kostakou P, Giannakopoulou V, Mihas C, Hatzigeorgiou G, Vasiliadis IK, Mikhailidis DP, Cokkinos DV: Apolipoprotein E gene polymorphism and obesity status in middle-aged men with coronary heart disease. In Vivo 2009, 23(1):33-39.

57. Liberopoulos EN, Miltiadous GA, Cariolou M, Kalaitzidis R, Siamopoulos KC, Elisaf MS: Influence of apolipoprotein E polymorphisms on serum creatinine levels and predicted glomerular filtration rate in healthy subjects. Nephrol Dial Transplant 2004, 19(8):2006-2012.

58. Karagiannides I, Abdou R, Tzortzopoulou A, Voshol PJ, Kypreos KE: Apolipoprotein $\mathrm{E}$ predisposes to obesity and related metabolic dysfunctions in mice. FEBS J 2008, 275(19):4796-4809.

59. Kypreos KE, Li X, van Dijk KW, Havekes LM, Zannis VI: Molecular mechanisms of type III hyperlipoproteinemia: The contribution of the carboxy-terminal domain of ApoE can account for the dyslipidemia that is associated with the E2/E2 phenotype. Biochemistry 2003, 42(33):9841-9853.

doi:10.1186/1476-511X-9-128

Cite this article as: Alvim et al: APOE polymorphism is associated with lipid profile, but not with arterial stiffness in the general population. Lipids in Health and Disease 2010 9:128. 